\section{Matéria \\ (2)}

ISSN 1517-7076
Revista Matéria, v. 17, n. 1, pp. 946 - 954, 2012

http://www.materia.coppe.ufrj.br/sarra/artigos/artigo11467

\title{
Biotransformação da cinza da casca de arroz em nanopartículas de sílica mediante Fusarium oxysporum
}

\author{
PINEDA, T. ${ }^{\text {I }}$ HOTZA, D. ${ }^{\text {I }, ~ S O A R E S, ~ C . H . L . ~}{ }^{\text {I }}$ CASAS, A. II , RAMIREZ, M. ${ }^{\text {II }}$, CORTÉS, V. II \\ ${ }^{\mathrm{I}}$ Ciência e Engenharia de Materiais (PGMAT), Universidade Federal de Santa Catarina (UFSC), \\ 88040-900 Florianópolis, SC, Brasil. \\ e-mail: dhotza@gmail.com \\ ${ }^{\text {II } U n i v e r s i d a d ~ P o n t i f i ́ c i a ~ B o l i v a r i a n a ~(U P B), ~ C i r c u l a r ~ 1 ~ \# 70-01, ~ M e d e l l i ́ n, ~ C o l o ̂ m b i a . ~}$ \\ e-mail: ana.casas@upb.edu.co ; tatianapinedavasquez@gmail.com ; chsoares@ccb.ufsc.br; margari- \\ ta.ramirez@upb.edu.co ; veronicacordesd@gmail.com
}

\section{RESUMO}

Neste estudo avaliou-se uma rota biológica à temperatura ambiente para a biotransformação da cinza da casca de arroz em nanopartículas de sílica empregando o fungo Fusarium oxysporum. Foram realizados ensaios e monitorou-se a produção de biomassa fúngica, $\mathrm{pH}$ e concentração de sílica solúvel em meio de cultura contendo cinza durante $270 \mathrm{~h}$ a uma temperatura de $25^{\circ} \mathrm{C}$, com uma concentração inicial de biomassa de $0,3 \mathrm{~g} / \mathrm{L}$ (base úmida) in situ. A cinza antes e após o tratamento foi analisada por espectroscopia de infravermelho IV; MEV e DRX. Os resultados deram indícios que com o processo biológico à temperatura ambiente ocorre uma biotransformação da cinza da casca de arroz, gerando sílica solúvel e cristalina no meio de cultura. Tais resultados indicam a possibilidade da síntese por via biológica de nanomateriais óxidos.

Palavras-chave: Cinza da casca de arroz, sílica, bioprocessamento, Fusarium oxysporum, nanomateriais.

\section{Biotransformation of rice husk ash in silica nanoparticles by Fusarium oxysporum}

\section{ABSTRACT}

In this study a biological route at room temperature for the biotransformation of rice husk ash (RHA) in silica nanoparticles using the fungus Fusarium oxysporum was evaluated. Some tests were carried out by monitoring the fungal biomass production, $\mathrm{pH}$, soluble silica on culture medium with rice husk ash and fungi, during $270 \mathrm{~h}$ at a $25^{\circ} \mathrm{C}$ temperature and $0.3 \mathrm{~g} / \mathrm{L}$ (wet basis) biomass concentration, in situ. The RHA was analyzed before and after processing by SEM and XRD. The results indicated that trhrough a biological process at room temperature a biotransformation of rice husk ash is reached by bioleaching and enzymatic action allowing the synthesis of oxidic nanomaterials.

Keywords: Rice husk ash, silica, bioprocessing, Fusarium oxysporum, nanomaterials

\section{INTRODUÇÃO}

A cinza da casca de arroz (CCA) é um subproduto agrícola empregado como biocombustível em diferentes processos como pirólise, gaseificação e combustão em leitos fixos e fluidificados especialmente em indústrias de beneficiamento de arroz [1-3] . A quantidade de sílica presente na CCA pode variar entre 80 e $97 \%$ dependendo das condições de queima e sua estrutura encontra-se, principalmente, na forma amorfa [1, 4].

A sílica é um material inorgânico empregado em uma ampla gama de aplicações comerciais como peneiras moleculares, suporte para catalisadores, materiais eletrônicos, assim como na indústria civil como pozolana no cimento e na produção de abrasivos de carbeto de silício, entre outros [4-7]. As partículas de sílica apresentam baixa densidade e alta resistência térmica e química. Com a diminuição no tamanho de partícula, a reatividade da sílica aumenta significativamente, facilitando, por exemplo, o processo de sinterização. Atualmente, a síntese de nanoestruturas da sílica é feita em condições extremas de $\mathrm{pH}$, usando produtos como $\mathrm{HCl}, \mathrm{H}_{2} \mathrm{SO}_{4}, \mathrm{HNO}_{3}, \mathrm{NaOH}$ e $\mathrm{NH}_{4} \mathrm{OH}$ [8]], além de pressões e temperaturas elevadas [9], eventual- 
mente em meios que apresentam toxidez [ $[\underline{8}, \underline{8}$. Normalmente, as quantidades produzidas são pequenas, e o material resultante apresenta características inconstantes, devido à dificuldade de controle da aglomeração.

Recentemente surgiram novas alternativas relacionadas com a biossilificação. Muitos organismos naturais produzem tecidos rígidos, como ossos, dentes, conchas, unidades esqueléticas e espículas. Normalmente, esses tecidos são dispositivos com funções mecânicas (por exemplo, estrutura, corte, polimento), ou físicas (por exemplo, magnética, óptica, piezoelétrica), ou ainda bioquímicas, servindo como fonte de íons para as atividades fisiológicas e, portanto, parte integrante do organismo [10].

Os tecidos rígidos são biocompósitos e incorporam em sua estrutura tanto macromoléculas (lipídeos, proteínas, polissacarídeos) como minerais (hidroxiapatita, carbonato de cálcio, sílica). Alguns organismos unicelulares (bactérias e algas) também produzem materiais inorgânicos de forma intra ou extracelular. Os exemplos mais importantes incluem esponjas diatomáceas, as quais sintetizam materiais silícicos [11-14]. Os fungos também podem ser empregados especialmente na produção de enzimas de forma extracelular para a biotransformação de diversos materiais como zircônia e titânia [15-16].

Recentemente Bansal et al. [17] apresentaram uma rota alternativa para obtenção de nanopartículas de sílica a partir da CA. A sílica amorfa presente na casca foi biotransformada à temperatura ambiente $\left(25^{\circ} \mathrm{C}\right)$ em partículas de 2-6 nm com formato semi-esférico, na forma cristalina usando um fungo filamentoso, denominado Fusarium oxysporum . Tal processo tem um potencial grande de aplicação, já que opera a $25^{\circ} \mathrm{C}$, sem usar produtos químicos.

O Fusarium oxysporum é um fungo fitopatógeno encontrado em solos, que vive saprofiticamente na matéria orgânica e em resíduos infectados. O micélio é incolor inicialmente, mas com a idade torna-se amarelo, rosa ou púrpura. Sua temperatura ótima de crescimento in vitro é de $28^{\circ} \mathrm{C}$ [18]. O Fusarium oxysporum é um microrganismo apropriado para a biossíntese de nanopartículas metálicas, capaz de sintetizar proteínas ou macromoléculas in vitro [15-17].

Portanto, este trabalho tem como objetivo apresentar a avaliação de uma rota biológica à temperatura ambiente para a biotransformação da cinza da casca de arroz em nanopartículas de sílica empregando o fungo Fusarium oxysporum.

\section{MATERIAIS E MÉTODOS}

\subsection{Materiais}

A CCA foi adquirida da Indústria e Comércio de Arroz Fumacense Ltda (Morro da Fumaça, SC, Brasil), não tendo sofrido nenhum processamento prévio antes de ser submetida ao processo de biotransformação.

O microrganismo empregado foi o Fusarium oxysporum fornecido pelo Centro de Estudios e Investigaciones en Biotecnologia (CIBIOT) da Universidad Pontificia Bolivariana (UPB), Medellin, Colômbia. O fungo foi mantido em meio de cultura sólido com extrato de batata e glicose em placas com incubação a $25 \pm$ $1{ }^{\circ} \mathrm{C}[18]$.

O meio de cultura aquoso, com $15 \mathrm{~g} / \mathrm{L}$ de extrato de malte (Hymedia) e $3 \mathrm{~g} / \mathrm{L}$ glicose (Hymedia), foi ajustado em pH 6,8 usando ácido clorídrico $1 \mathrm{M}$ (Vetec) e hidróxido de sódio $1 \mathrm{M}$ (Vetec) e posteriormente esterilizado em autoclave com 1 atm de pressão, durante 20 min [17].

Para a obtenção da curva padrão de sílica solúvel em espectrometria, foi empregada uma solução aquosa de silicato de sódio concentrada (10 ppm) preparada a partir de silicato de sódio $99.8 \%$ (Vetec), e posteriormente foram feitas diluições com água deionizada correspondentes a 0,$2 ; 0,4 ; 0,6 ; 0,8$ e $1 \mathrm{ppm}$, respetivamente.

\subsection{Métodos}

As curvas de crescimento do fungo foram determinadas em meio líquido com e sem presença de CCA e silicato de sódio puro (Vetec) durante um período total de 11 dias, através do método gravimétrico. Em frascos erlenmeyers de $250 \mathrm{~mL}$ foram colocados $100 \mathrm{~mL}$ de meio de cultura líquido e $0,03 \mathrm{~g}$ de micélio. $\mathrm{O}$ pH inicial foi ajustado para 6,8 com hidróxido de sódio $(\mathrm{NaOH}) 1 \mathrm{M}$ e ácido clorídrico $(\mathrm{HCl}) 1 \mathrm{M}$. O micélio foi retirado da cultura, lavado com água deionizada e finalmente pesado. Simultaneamente foi registrada a variação do $\mathrm{pH}$ de cada amostra.

A quantificação da sílica solúvel foi feita mediante a formação de um complexo betamolibdosilicato de coloração amarela, com uma solução molibdato de amônio com pH ácido na faixa de 1,4 a 2,0. Para cada $2,5 \mathrm{~mL}$ de amostra foram adicionados $0,1 \mathrm{~mL}$ de solução aquosa de molibdato de amônio $(0,1 \mathrm{~g} / \mathrm{mL})$ e $0,05 \mathrm{~mL}$ de $\mathrm{HCl} 1 \mathrm{M}$. A solução foi agitada e deixada em repouso por $10 \mathrm{~min}$. Na sequência, foi adicionado $0,1 \mathrm{~mL}$ de solução de ácido oxálico $(3 \mathrm{~g} / \mathrm{L})$ o qual promove a mudança da coloração amarela para azul por efeito da redução do complexo. Então, a solução foi agitada novamente e posta em repouso por 1 
hora. Finalmente, a leitura foi feita em espectrofotômetro UV-Visível (Pró-Análise V-1200) com comprimento de onda de $660 \mathrm{~nm}$ [19]. Para a obtenção da curva padrão, foi empregada uma solução aquosa de silicato de sódio com concentrações de $\mathrm{SiO}_{2}$ correspondentes a 0,2;0,4;0,6;8 e 1 ppm respetivamente, usando o procedimento anterior.

Para a técnica de espectroscopia de infravermelho, foram tomadas amostras antes e depois do tratamento da CCA com o fungo Fusarium oxysporum. As amostras foram incorporadas por prensagem em pastilhas de $\mathrm{KBr}$ e analisadas em espectrômetro IV (ABB, FTLA 2000), com a finalidade de observar a biotransformação nos grupos funcionais da CCA.

Um difratômetro de raios X (Philips, X-Pert) foi empregado para a caracterização das fases cristalográficas da CCA antes e depois do tratamento com o fungo. As análises foram realizadas em amostras na forma de pó, sem nenhum tipo de preparação prévia, no intervalo de medida de $2 \theta$ entre 3 e $120^{\circ}$.

Por fim, foi realizada uma análise por microscopia eletrônica de varredura (JEOL JSM-6390LV). As amostras foram dispostas sobre uma fita de carbono e, por não possuírem caráter condutor, foram metalizadas com uma fina camada de ouro, para visualizar as estruturas da CCA antes e após o tratamento empregando o fungo [17].

\section{$3 \quad$ RESULTADOS E DISCUSSÃo}

\subsection{Análise da Curva de Crescimento}

O meio de cultura desempenha um papel importante para as diferentes aplicações dos microrganismos [20]. A curva de crescimento do fungo Fusarium oxysporum é apresentada na Figura 1, onde nas primeiras 114 horas (aproximadamente 4 dias) o microrganismo encontrou-se na fase lag, definida como um período onde não há quase variação na população de fungo [20]. Para os diversos ensaios realizados, uma vez superada essa etapa, o $F$. oxysporum apresentou uma fase exponencial acelerada de crescimento no meio de cultura com $20 \mathrm{~g} / \mathrm{L}$ de CCA que contém principalmente $\mathrm{SiO}_{2}$ e outros elementos em baixas concentrações como $\mathrm{Na}, \mathrm{K}, \mathrm{Fe}, \mathrm{Mg}, \mathrm{Mn}, \mathrm{Al}$. Esses elementos podem estimular o crescimento pois são considerados como essenciais para várias funções [21]. Após 174 horas (7 dias) o estágio final conhecido como fase estacionária, caracterizada pela escassez de nutrientes, começa a aparecer, especialmente para o meio de cultura contendo CCA. Esses resultados indicam que o fungo cresceu rapidamente e em maior quantidade no meio de cultura com CCA e que não foram observadas mudanças significativas no crescimento do fungo entre os meios de cultura com silicato de sódio e o meio de cultura sem aditivos.

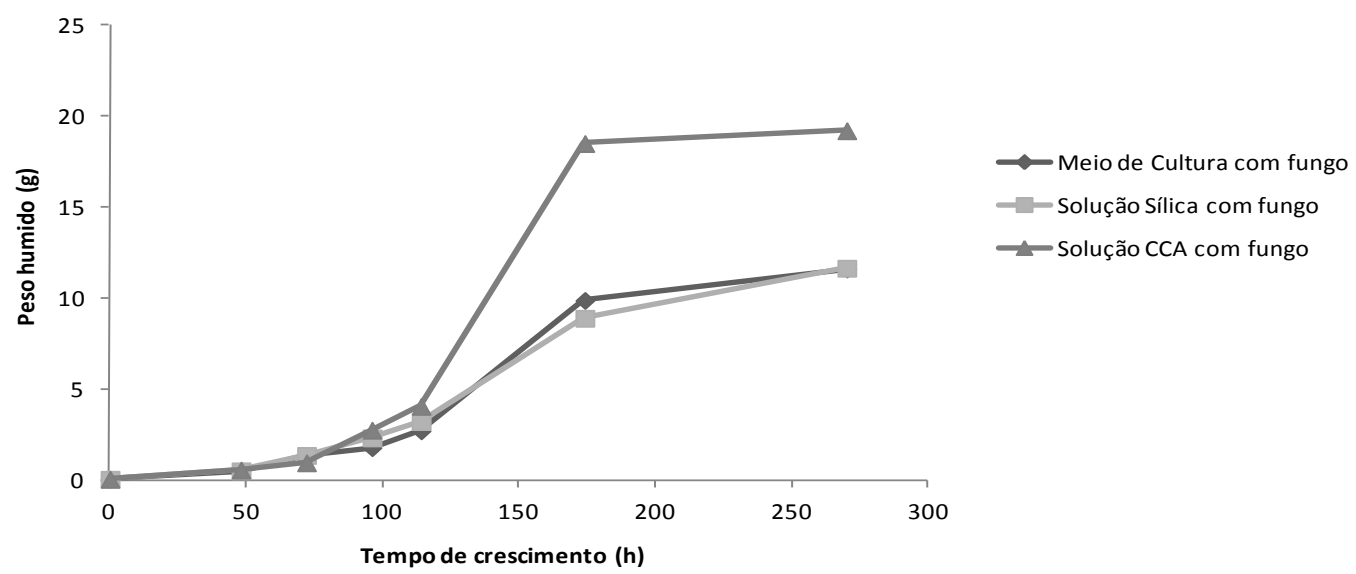

Figura 1: Curva de crescimento do fungo Fusarium oxysporum.

\subsection{Análise da Variação do Ph}

A variação do $\mathrm{pH}$ em diferentes ensaios foi avaliada em função do tempo. Foram verificadas as condições dos meios contendo tanto sílica como CCA sem adição de biomassa, para descartar mudanças do $\mathrm{pH}$ por fatores externos à ação microbiana. Ao longo do experimento, o pH permaneceu em torno de 6,1, enquanto a maior queda foi observada no sistema contendo unicamente o fungo sem a presença de fontes de 
sílica, até atingir um valor de 3,5. Na Figura 2 são mostrados os diferentes perfis de variação de pH. A tendência geral do F. oxysporum é diminuir o $\mathrm{pH}$ ao longo do tempo. Esse comportamento pode ser explicado a partir da formação de ácidos. BACON et al. [22] observaram a capacidade das espécies Fusarium de produzir ácidos, especialmente o fusárico.

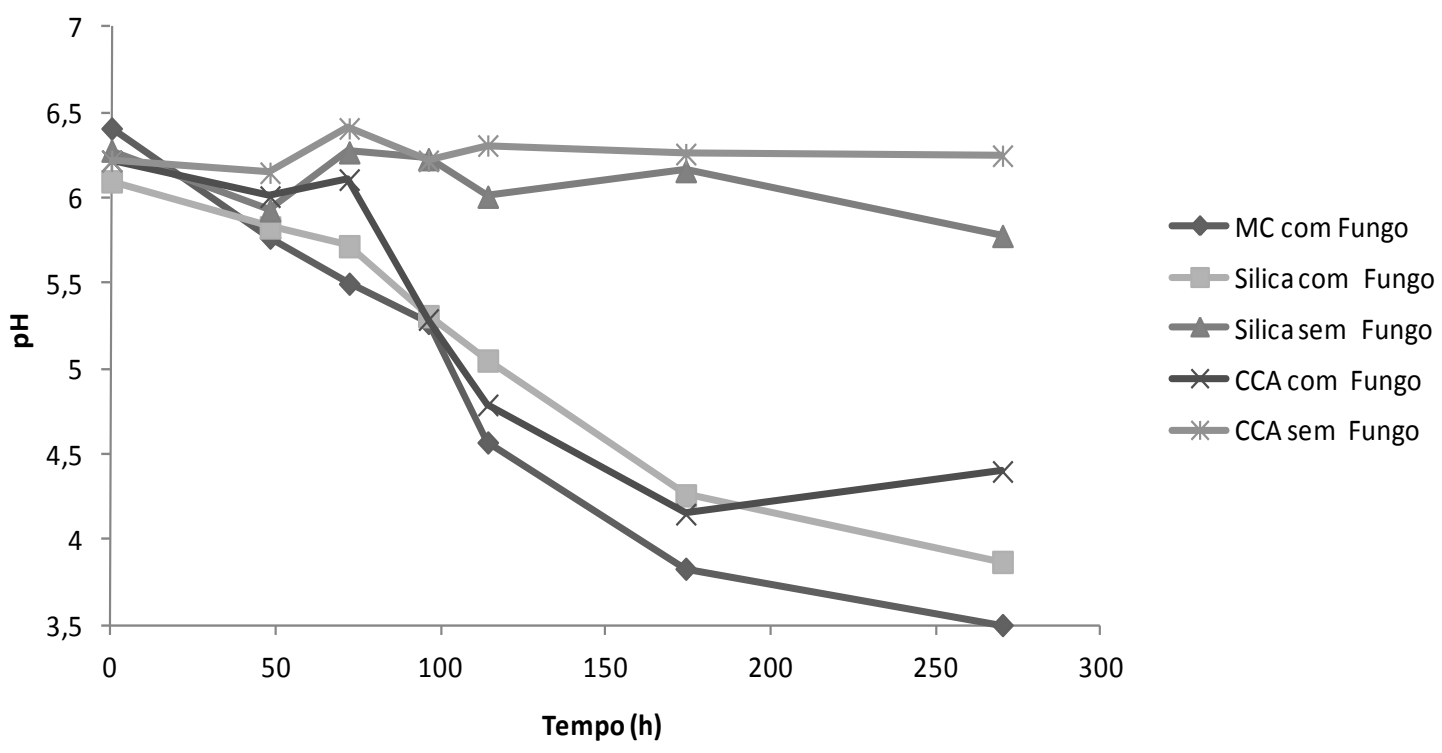

Figura 2: Variação do pH durante o processo de biotransformação da CCA pela ação do Fusarium oxysporum.

\subsection{Análise da Sílica Solúvel}

Na Figura 3 e Figura 4 são apresentadas a curvas de concentração de sílica solúvel em função do tempo para soluções com cinza da casca de arroz, silicato de sódio e meio de cultura com e sem microrganismo.

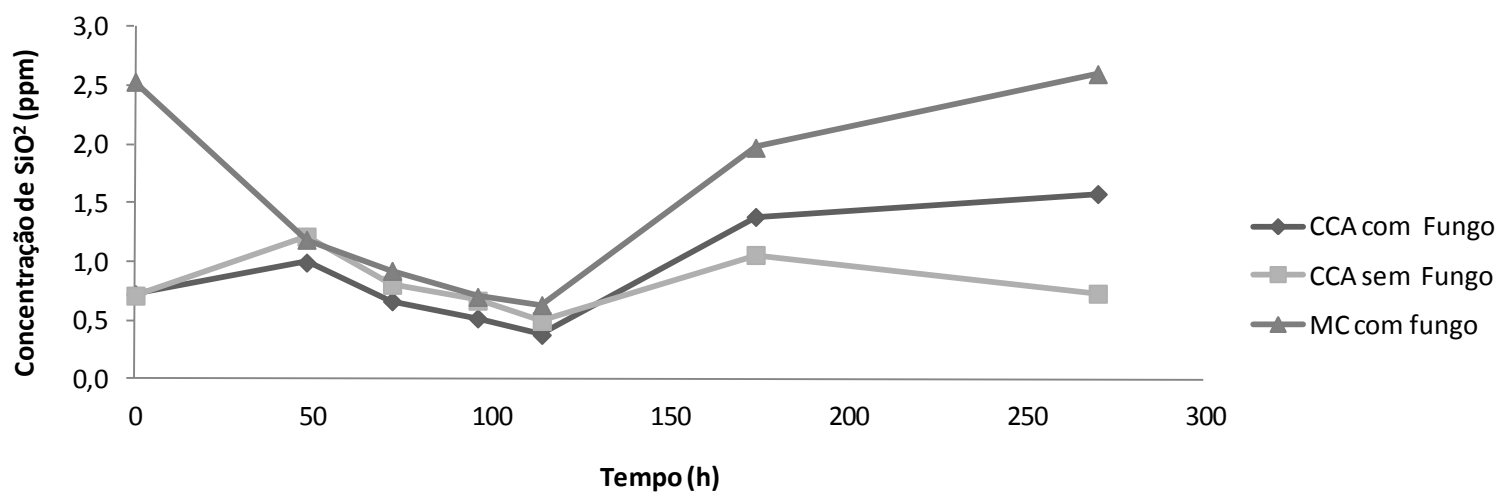

Figura 3: Concentração de sílica solúvel em função do tempo para soluções de CCA com e sem Fusarium oxysporum e meio de cultura com presença de Fusarium oxysporum.

Nas primeiras 120 horas, observa-se que o microrganismo está num processo de adaptação. Logo após este processo, começa a disponibilização da sílica no meio líquido. Segundo Bansal et al. [17], formamse então nanopartículas esféricas de sílica. O período de disponibilização da sílica corresponde à fase exponencial do $F$. oxysporum, que é o período onde se tem maior quantidade de biomassa e de enzimas excretadas extracelularmente pelo Fusarium oxysporum para a lixiviação seletiva de sílica, assim como a geração de 
proteínas que estabilizam as partículas $[\underline{17}, \underline{23}, \underline{24}]$. No processo onde somente se tem o meio de cultura (Figura 3), observam-se variações na concentração de sílica, pois o microrganismo empregado foi obtido de uma placa de Petri com meio de cultura sólido na presença de CCA com a finalidade de diminuir o tempo de adaptação à sílica.

Na Figura 4 são apresentados os resultados obtidos dos ensaios realizados empregando duas soluções de silicato de sódio com uma concentração inicial de 10 ppm de $\mathrm{SiO}_{2}, 15 \mathrm{~g} / \mathrm{L}$ de extrato de malte e $3 \mathrm{~g} / \mathrm{L}$ de glicose, com e sem a presença do Fusarium oxysporum. Ambas as curvas apresentaram um comportamento similar com concentrações de sílica entre 40 e $50 \mathrm{ppm}$. Presume-se que o microrganismo, além de disponibilizar a sílica ao meio, atua como agente modificador na estrutura da sílica presente no silicato de sódio, o que está de acordo com resultados reportados na literatura [17].

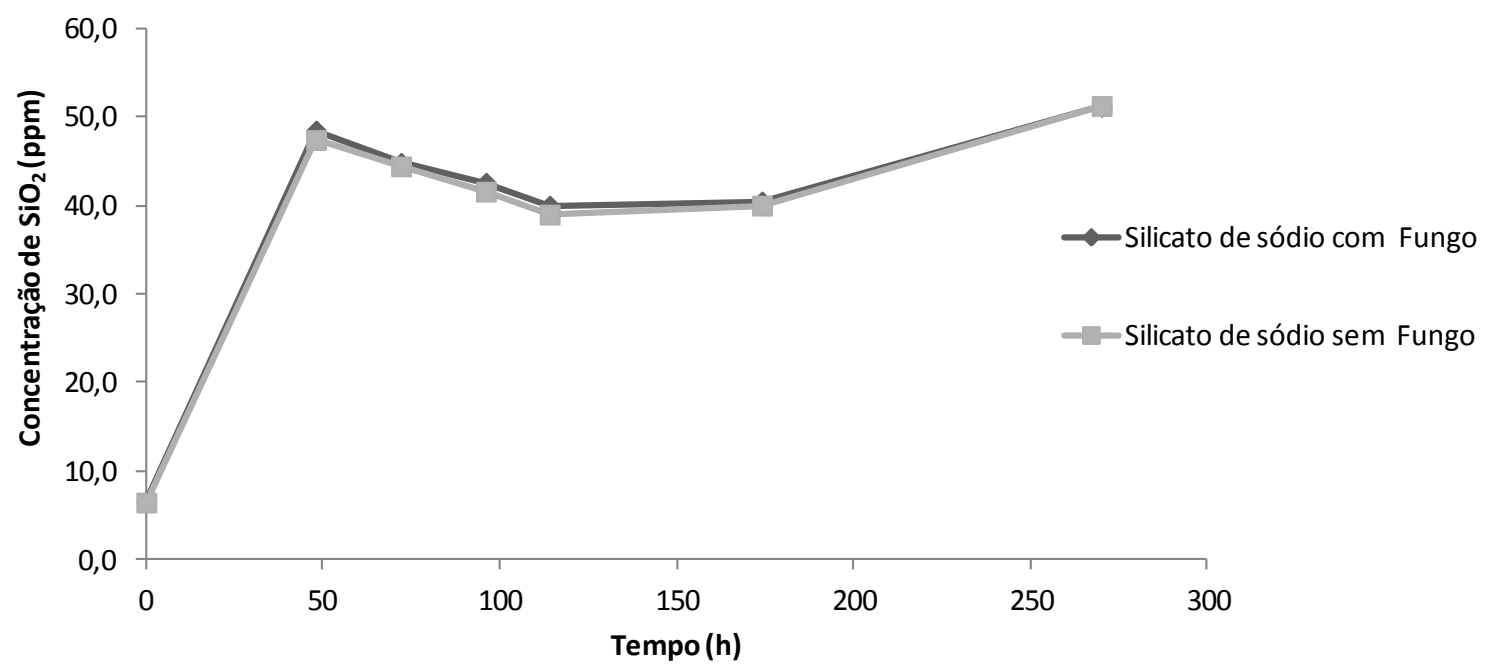

Figura 4: Concentração de sílica solúvel em função do tempo para soluções de silicato de sódio com e sem Fusarium oxysporum.

\subsection{Análise dos Grupos Funcionais da CCA antes e após a Biotransformação}

A cinza da casca de arroz foi analisada por espectrofotometria de IR, que permitiu obter os picos de absorção característicos da cinza antes e depois do tratamento empregando $F$. oxysporum. A maioria dos picos relacionados com a sílica está compreendida entre os comprimentos de onda 500 e $1250 \mathrm{~cm}^{-1}$. Em ambos os casos, a mudança mais importante está no halo entre 950 e $1250 \mathrm{~cm}^{-1} \mathrm{com}$ pico máximo em $1070 \mathrm{~cm}^{-1}$, que pode ser observado na

Figura 5, associada com o modo vibracional de estiramento das moléculas assimétricas Si-O-Si [17, 25]. Esse halo está presente em menor intensidade na CCA tratada, devido possivelmente à lixiviação de partículas de sílica ao meio aquoso [17]. Os picos associados a comprimentos de onda de 540 e $800 \mathrm{~cm}^{-1}$ estão relacionados ao modo de balanço e flexão de $\mathrm{SiO}_{2}$, respectivamente. O pico ao redor de $2300 \mathrm{~cm}^{-1}$ está associado às impurezas da CCA.

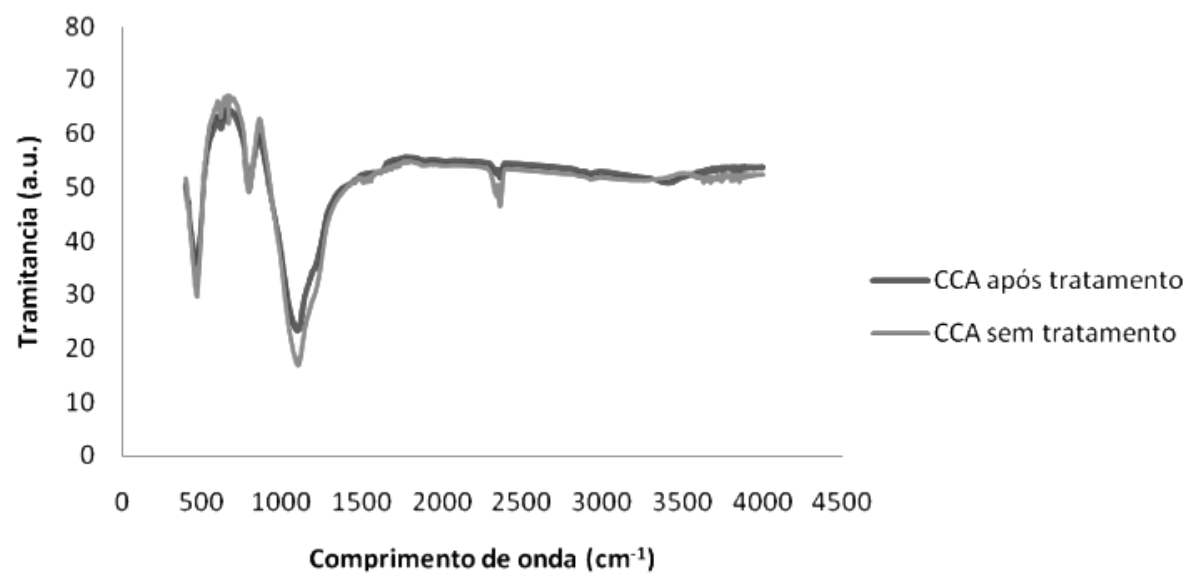


Figura 5: Espectro de infravermelho da CCA antes e após o tratamento com o Fusarium oxysporum.

\subsection{Determinação da Composição de Fases da CCA}

Na Figura 6 e Figura 7 respectivamente, a sílica presente na cinza manteve-se predominantemente amorfa e apresentou um halo de baixa intensidade entre 15 e $30^{\circ}$, de acordo com relatos encontrados na literatura [1, 3], este halo é típico da forma estrutural da CCA.

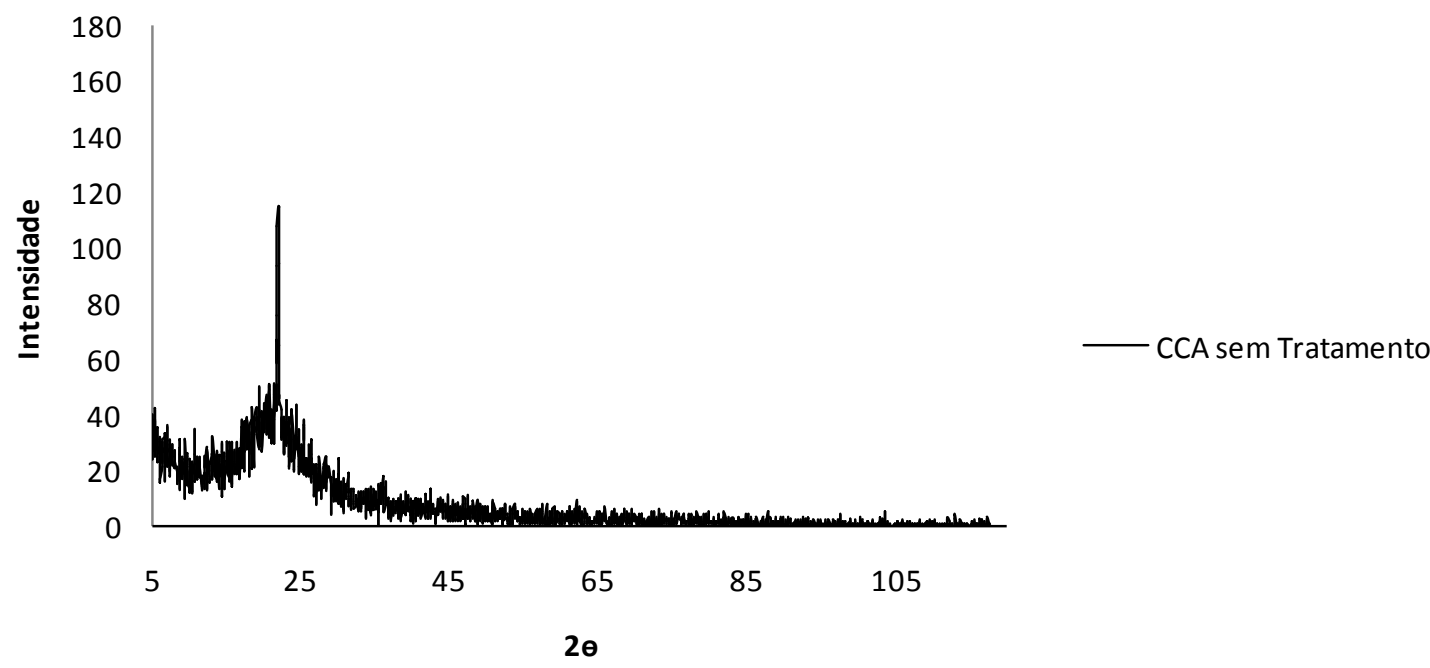

Figura 6: Difratograma da cinza da casca de arroz

Na Figura 7, picos correspondentes à cristobalita, em torno de $22^{\circ}$ e $37^{\circ}$ começam a evidenciar-se com maior intensidade após o tratamento com o fungo. Provavelmente a ação do fungo é já significativa a temperaturas baixas $\left(28^{\circ} \mathrm{C}\right)$ e pressão atmosférica. Resultados semelhantes empregando casca de arroz foram encontrados por Bansal et. al. [17].

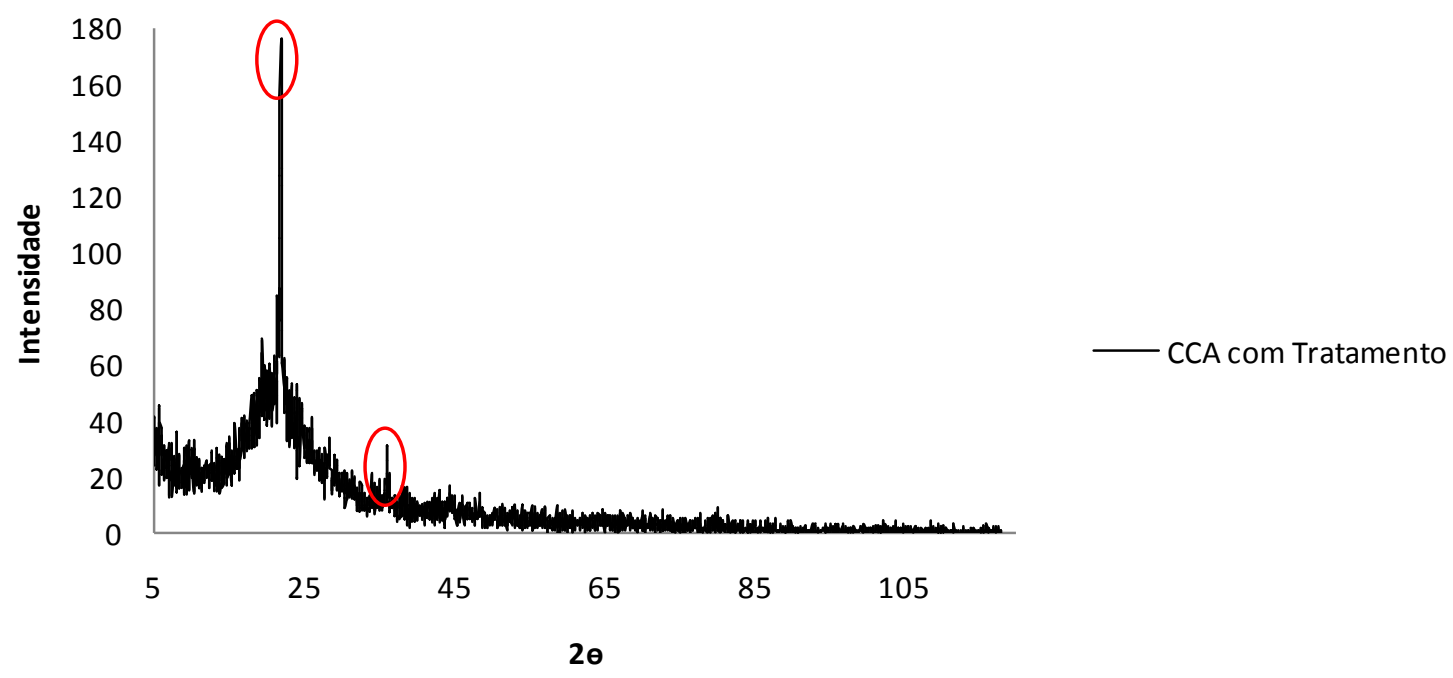

Figura 7: Difratograma da cinza da casca de arroz após o tratamento com Fusarium oxysporum à temperatura de $28^{\circ} \mathrm{C}$, pressão atmosférica. Picos destacados correspondem à cristobalita. 


\subsection{Análise da Microestrutura das Partículas da CCA}

As micrografias obtidas por MEV das partículas de CCA permitiram identificar uma estrutura lamelar e porosa (Figura 1, Figura 8 a, c, e), atribuída à oxidação dos compostos orgânicos que foram convertidos em gases durante o processo de combustão [1]. Nessas micrografias, Figura 8(a, b, e, f), também pode ser vista a ondulação da epiderme externa, região que concentra o maior percentual de sílica [1, 2, 24]. A Figura 8(c, d) mostra, com maior detalhamento, a epiderme interna de uma das partículas de casca de arroz presente na cinza, antes e depois do tratamento. Nota-se uma estrutura celular e porosa conhecida como esqueleto de sílica, resultante da remoção da lignina e celulose durante a queima [2] e que coincide com a área de menor mudança estrutural, possivelmente por apresentar menor concentração de sílica em relação à parte externa da CCA [2].

Após o tratamento com o fungo Fusarium oxysporum, foi notado um aumento na porosidade (Figura 8. b, c, d), provavelmente devido ao desprendimento de partículas estruturadas da sílica pela ação do microrganismo. Os mecanismos podem ser atribuídos à ação enzimática e lixiviação ácida. [또, 17, 23] .

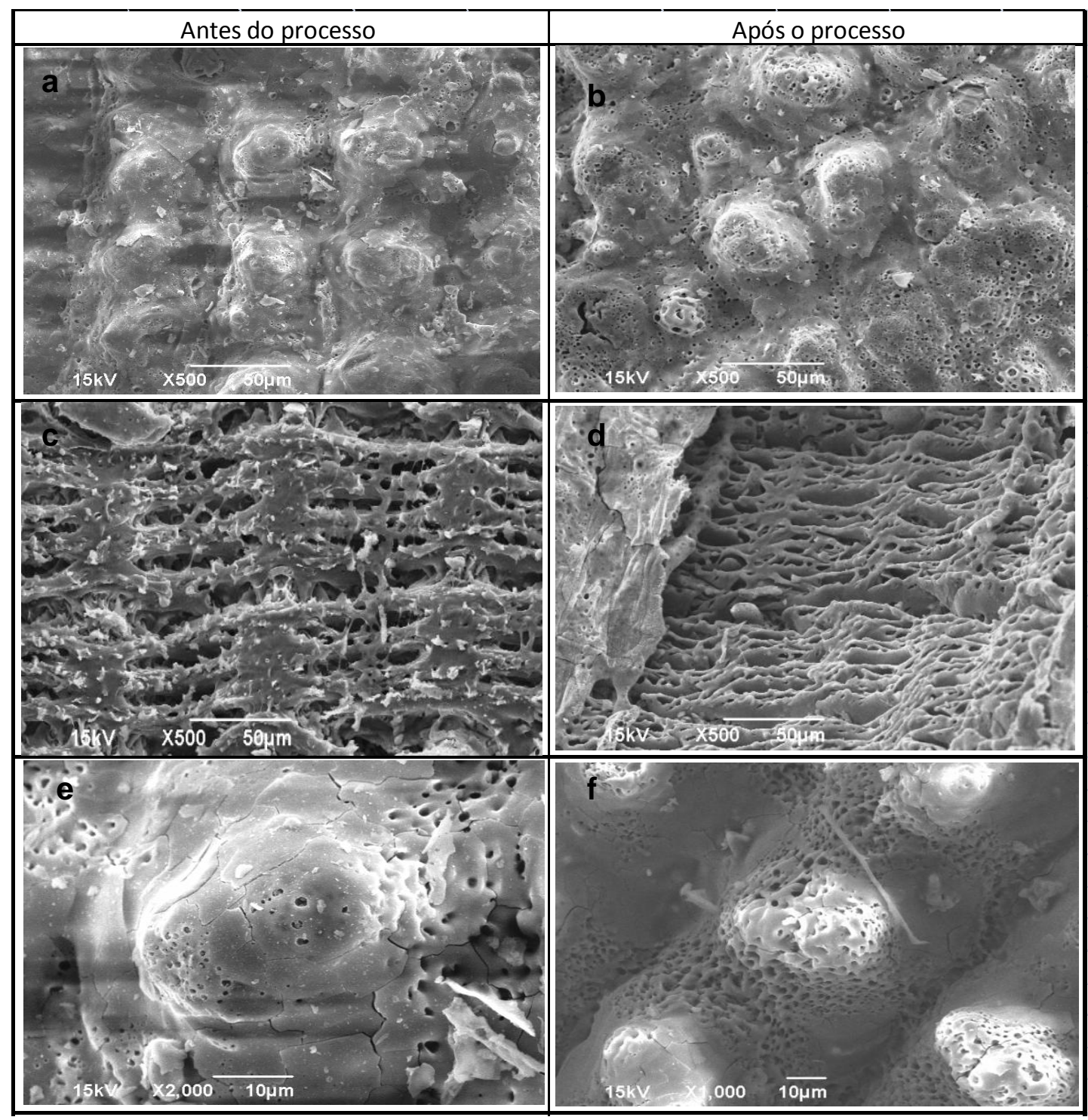

Figura 8: Micrografias da Cinza da casca de arroz antes (a,c, e) e após o tratamento com Fusarium oxysporum à $28^{\circ} \mathrm{C}$ e pressão atmosférica $(\mathrm{b}, \mathrm{d}, \mathrm{f})$ 


\section{CONCLUSÃO}

Em conclusão, foi possível observar que o fungo Fusarium oxysporum pode ser usado para biotransformar a sílica amorfa presente na cinza da casca de arroz através da ação microbiana.

O fungo Fusarium oxysporum apresenta uma maior taxa de crescimento no meio de cultura contendo CCA. O tempo para chegar à fase estacionaria é de aproximadamente 11 dias. Uma produção de biomassa ao redor de $20 \mathrm{~g} / \mathrm{L}$ foi obtida. Para diminuir a fase lag, que é de aproximadamente 4 dias, é necessário empregar outros mecanismos de indução.

A síntese de nanomateriais óxidos à temperatura ambiente é possível mediante o uso de microrganismos e de resíduos agroindustriais. O método proposto apresenta baixo custo e de baixo impacto ambiental. A sílica formada tem possibilidade de ser empregada na indústria da construção civil como elemento de reforço a baixas idades de hidratação, o que está sendo pesquisado na continuidade deste trabalho.

\section{AGRADECIMENTOS}

Os autores agradecem às agências CNPq e COLCIENCIAS através do convenio bilateral de pesquisa entre Brasil e Colômbia, processo 490166/2009-1, pelo suporte financeiro.

\section{BIBLIOGRAFIA}

[1] MARTINEZ, A.J.D., PINEDA, V.T.G., JUNKES, J.A., et al., "Caracterização de cinza obtida por combustão de casca de arroz em reator de leito fluidizado", Química Nova, v. 32, n. 5, pp. 1110-1114, 2009.

[2] DELLA, V.P, HOTZA, D., JUNKES, J.A., et al. "Estudo comparativo entre sílica obtida por lixívia ácida da casca de arroz e sílica obtida por tratamento térmico da cinza de casca de arroz", Química Nova, v. 29, n. 6, pp. 1175-1179, 2006.

[3] DELLA, V.P., KUHN, I., HOTZA, D., "Caracterização de cinza de casca de arroz para uso como matéria-prima na fabricação de refratários de sílica”, Química Nova, v. 24, n. 6, pp. 778-782, 2001.

[4] CHANDRASEKHAR, S., PRAMADA, P.N., PRAVEEN, L., "Effect of organic acid treatment on the properties of rice husk silica”., Journal of Materials Science, v. 40, pp. 6535-6544, 2005.

[5] SILVA JR, J., Obtenção de xerogel de sílica a partir das cascas de arroz em uma aproximação bottomup para produção de materiais em eletrônica, Tese de M.Sc., UFSC, Florianópolis, SC, 2009.

[6] KALAPATHY, U., PROCTOR, A., SHULTZ, J., “A simple method for production of pure silica from rice hull ash", Bioresource Technology, v. 73, pp. 257-262, 2000.

[7] LIOU, T.H., "Preparation and characterization of nano-structured silica from rice husk", Materials Science and Engineering A, v. 364, pp. 313-323, 2004.

[8] CHAKRAVERTI, A., MISHRA, P., BANERJEE, H.D. "Investigation of combustion of raw and acidleached rice husk for production of pure amorphous white silica", Journal of Materials Science, v. 23, pp. 21-24, 1988.

[9] RAMARAO, G., SASTRY, A., ROHATGI, P.K. "Nature and reactivity of silica available in rice husk and its ashes", Bulletin of Materials Science, v. 12, pp. 469, 1989.

[10] SARIKAYA, M. "Biomimetics: Materials fabrication through biology", PNAS, v. 96 n. 25, pp. 1418314185, December 1999.

[11] XIANG, T., CHOW, S.K., ZHANG, D., "Biomorphic mineralization: from biology to materials", Progress in Materials Science, v. 54, n.5, pp. 542-659, 2009.

[12] CHERYL, W., HUANG, J., KAPLAN, D., "Lessons from seashells: silica mineralization via protein templating”, Trends in Biotechnology, v. 22, n. 11, pp.577-585, November 2004. 
[13] LIKHOSHWAY, Y.V., SOROKOVIKOVA, E.G., BELYKH, O.I., et al, "Visualization of the silicon biomineralization in cyanobacteria, sponges and diatoms", Biosphere Origin and Evolution, part III pp. 219-230, 2008.

[14] EHRLICH, H., DEMADIS, K.D., POKROVSKY, O.S., et al. "Modern views on decalcification: biosilica and biotic silica dissolution in natural and artificial environments", Chemical Reviews, v. 110, pp. 4656-4689, August 2010.

[15] BANSAL, V., RAUTARAY, D., AHMAD, A., et al, "Biosynthesis of zirconia nanoparticles using the fungus Fusarium Oxysporum", Journal of Materials Chemistry, v. 14, n. 22 pp. 3303-3305, 2004

[16] BANSAL, V., PODDAR, P., AHMAD, A., et al, "Room-temperature biosynthesis of ferroelectric barium titanate nanoparticles", Journal of the American Chemical Society, v. 128, n. 36, pp. 1195811963, 2006.

[17] BANSAL, V., AHMAD, A., SASTRY, M. "Fungus-mediated biotransformation of amorphous silica in rice husk to nanocrystalline silica", Journal of the American Chemical Society, v. 128, n. 43, pp. 14059-14066, 2006.

[18] DALMAGRO, J., Associação de Trichoderma sp. e fungicidas no controle de Fusarium oxysporum $f$. sp. Phaseoli, Tese de M. Sc., UFRGS, Porto Alegre, RS, 2007.

[19] EATON, A.D., GREENBERG, A.E., FRANSON, M.A.H et al., Standard methods for the examination of water and wastewater, 19th ed. pp.1325, ISBN 0875532233, American Public Health Association, Washington, DC, 1995.

[20] CASAS, A.E, TOREM, M, SOUZA L., "Fundamental studies of Rhodococcus opacus as a biocollector of calcite and magnesite”, Minerals Engineering, v. 20, n. 10, pp. 1026-1032, August 2007.

[21] MITCHELL, R, GU, D., Environmental microbiology, 2a Ed., Wiley Blackwell., Hong Kong. 2009.

[22] BACON, C.W., PORTER, J. K., NORRED, W. P., et al., "Production of fusaric acid by Fusarium Species", Applied and Evironmental Microbiology, v. 62, n. 11, pp. 4039-4043, November 1996.

[23] GADE, A., INGLE, A., WHITELEY, C., et al., "Mycogenic metal nanoparticles: progress and applications", Biotechnology Letters, v. 32, n. 5, pp.593-600, May 2010.

[24] ROZAINEE, M., NGO, S.P., ARSHAD, A.S., et al. "Fluidized bed combustion of rice husk to produce amorphous siliceous ash", Bioresource Technology, v. 12, n. 1, pp 33-42, March 2008.

[25] UMEDA, J., KONDOH, K. "High-purification of amorphous silica originated from rice husks by combination of polysaccharide hydrolysis and metallic impurities removal", Industrial Crops and Products, v. 32, n. 3, pp. 539-544, 2010. 